\title{
REFERENCE VALUES FOR FETAL HEART RATE IN CATTLE IN THE FIRST TRIMESTER OF PREGNANCY
}

\author{
Lea LÉNÁRT ${ }^{1,2}$, Marcel TAVERNE ${ }^{3}$, Peter WOLLESWINKEL ${ }^{3}$, Zoltán GUBIK ${ }^{4}$, \\ László MOLNÁR ${ }^{2}$ and Ottó SZENCI ${ }^{1,2^{*}}$ \\ ${ }^{1}$ University of Veterinary Medicine Budapest, Department and Clinic for Production \\ Animals, H-2225 Üllő, Dóra major, Hungary; ${ }^{2}$ MTA-SZIE Large Animal Clinical \\ Research Group, Üllő, Hungary; ${ }^{3}$ Utrecht University, Department of Farm Animals, \\ Utrecht, The Netherlands; ${ }^{4}$ DPMG Co. Ltd., Cegléd, Hungary
}

(Received 4 February 2019; accepted 2 May 2019)

\begin{abstract}
The aim of this study was to create a fetal heart rate (FHR) reference curve for singleton bovine fetuses in the first trimester of gestation and to determine its possible relationship with the outcome of pregnancy. Forty-eight HolsteinFriesian cows with one fetus and five cows with twins were used. Fetal heart beatings were recorded on videotape during transrectal scanning with a 5 and/or 7.5 MHz linear array transducer on a weekly basis between Days 40 and 95 of gestation. FHR was calculated by averaging the results of five counts of the same record by the same observer. For singleton pregnancies, a reference curve was created using the mean, the standard deviation (SD) and the 5th and 95th percentiles. The FHR increased from Days 40-46 (173 beats/min) to Days 61-67 (183 beats/min). After a peak, the FHR decreased slowly until Days 89-95 (175 beats/min), while the SD increased. There was no significant difference between singleton and twin fetuses. In the aborted and lost fetuses in twin gestation due to fetal reduction, both bradycardia and tachycardia were detected compared to the singleton pregnancy reference curve.
\end{abstract}

Key words: Ultrasonography, fetal heart rate, singleton and twin pregnancy, dairy cattle

Ultrasonography has been widely used for pregnancy diagnosis in cattle, but it also makes it possible to determine the viability of the embryo/fetus by checking the heartbeat or measuring the fetal heart rate (FHR) (Curran, 2000).

There is a paucity of information regarding the FHR in the cow. In one experiment, the heart rate (HR) of a bovine embryo on Day 20 was about 170 beats/ min, which then decreased to 150 beats/min at Day 26 (Curran et al., 1986). In another study, an increase was seen from Day 23, when the HR was approximately 138 beats/min until Days 49 to 60, when it peaked at 190 beats/min

*Corresponding author; E-mail: Szenci.Otto@univet.hu; Phone: 0036 (29) 521-301; Fax: 0036 (29) 521-385 
(Ginther, 1998). Other authors observed a decrease in the FHR from Day 60 till the 5th-9th month of gestation, and registered variability in the FHR of the same fetus at different times of examination (Kähn, 1989). More recently, HR was measured in six 15-18 months old pregnant heifers and in seven cows of the Holstein-Friesian breed. In the heifers, the FHR decreased progressively in a quadratic pattern from Day 31 (182 beats/min) to Day 80 (156 beats/min), while in the cows it changed in an approximately stable or intermittent range (Kheradmand et al., 2005).

Hardly any data can be found in the literature regarding the FHR in twin pregnancies. Although a significant difference was reported between in vivo singletons and in vitro derived twins (Bertolini et al., 2002), it is not certain that these results are comparable with the HR of fetuses after AI.

There is also a paucity of information about the changes in the FHR when embryonic/fetal mortality occurs. In one study, an apparent reduction in FHR prior to embryonic death was observed in two heifers (Kastelic et al., 1988). In another study, one cow that aborted at Day 182 showed a higher FHR between Days 50 and 80 than the healthy fetuses in the control group (Oztekin et al., 2009). In heifers that were treated with the anti-progesterone aglepristone twice at Days 47 and 48 of gestation, a non-significant drop in FHR around $8 \mathrm{~h}$ before fetal death was detected in four of five treated animals (Breukelman et al., 2005). These results suggest that the FHR might be a diagnostic tool to predict fetal loss in cattle.

Twin pregnancy is a major risk factor for late embryonic and early fetal mortality. Silva-del-Río et al. (2009) found that while in singleton pregnancies the embryo's chance of survival is $91.9 \%$, in case of twin pregnancies it is $75.5 \%$. According to another study the likelihood of late embryonic and early fetal mortality in twin pregnancies was 3-7 times higher than in single pregnancies (López-Gatius and Garcia-Ispierto, 2010). A factor contributing to this might be that while in singleton pregnancies the period of risk for early fetal mortality ends at Day 60 of pregnancy, in twin pregnancies this period is longer, and it can last up to Day 90 of pregnancy (López-Gatius and Garcia-Ispierto, 2010). To the best of the authors' knowledge, no data are available on the FHR in twin pregnancies that resulted in fetal loss.

The aim of the present study was to create a reference FHR curve for singleton bovine fetuses between Days 40 and 95 of gestation and to determine if the pregnancy outcome has any relation with the FHR pattern. A further objective was to detect if there is any difference in FHR patterns between fetuses of singleton and twin pregnancies. In twin pregnancies, the possible relationship between pregnancy outcome and FHR was also examined. 


\section{Materials and methods}

\section{Animals}

Sixty-one pregnant Holstein-Frisian cows were used in the study. Fifty-six of them carried one fetus, and five carried two fetuses. Pregnancy was checked at Day 40 after AI by means of transrectal ultrasonography using 5 and $7.5 \mathrm{MHz}$ linear array transducers (Pie Medical scanner 100 Falco, Maastricht, The Netherlands). At the time of the examination it was also determined if any adhesions or clinical abnormalities of the genital tract were present, which could impede the performance of the investigation at subsequent stages of pregnancy. Eight cows with a singleton pregnancy were excluded from the analysis because they were culled (for various reasons) before calving. Thus, 48 cows with a singleton pregnancy and five cows with twins were finally used in the study.

The care of the animals and the experimental design of the study were approved by the Local Animal Ethics Committee in Budapest, Hungary.

\section{Measurement of the fetal heart rate (FHR)}

Ultrasonographic examinations of the pregnant cows were performed on a weekly basis between Days 40 and 95 of gestation during a period of maximum eight weeks. Transrectal ultrasonographic scanning was performed until approximately Day 65 using both a $5.0 \mathrm{MHz}$ and a $7.5 \mathrm{MHz}$ linear array transducer. After Day 65 only a $5.0 \mathrm{MHz}$ linear array transducer was used. In twin pregnancies, the location of each fetus was determined (left/right uterine horn, caudal/cranial in a uterine horn) and recorded. The sex of the fetuses was also determined so to enable the postpartal checking of which fetus was lost.

Ultrasonographic images were recorded on videotape and analysed offline by the same observer. The FHR (in beats/minute) was determined by counting the number of heartbeats while measuring the duration of the video recording with a stopwatch. Mean FHR was calculated by averaging five times counting of the same recording. In singleton pregnancies the FHR was counted with a mean duration of 14.6 seconds, and $89.4 \%$ of the records had a duration exceeding 10 seconds. In twins, the mean duration was 14.4 seconds and the majority of the counts had a duration of more than 10 seconds $(80.8 \%)$.

The FHR patterns of the normal fetuses of twin pregnancies were compared with the reference curve of 43 singleton fetuses (fetuses which were not lost and not carried by a Johne's disease positive tested cow, were regarded as normal).

\section{Statistical analysis}

In singleton pregnancies, the data were analysed by calculating the mean, the standard deviation (SD) and the 5th and 95th percentiles of the FHR values. The reference curve was obtained by excluding the cows that aborted or suffered 
from a (sub)clinical disease and exceeded the 5th or 95th percentile. To reveal whether or not the FHR depends on the twin status and pregnancy time, the FHR data were analysed according to twin status (singleton or twin) and pregnancy time (days) with Stata 14 using a mixed linear model (xtmixed heartbeats twin days || twinid:) (Rabe-Hesketh and Skrondal, 2012). The twin identifier (first or second twin) was regarded as a nuisance parameter.

\section{Results}

During the study, a total number of 330 FHR recordings of 43 healthy cows with a single fetus were performed. Five of the initial 48 cows were excluded, three because of abortion and two because they were diagnosed with Johne's disease after calving. Table 1 presents the number of fetuses examined at different time points, the mean FHR for gestational age, the standard deviation and the 5th and 95 th percentiles.

\section{Table 1}

Fetal heart rate (beats/minute) based on 330 records at weekly intervals

\begin{tabular}{lccccc}
\hline Days of gestation & $\mathrm{n}$ & Mean (beats/minute) & SD & $\begin{array}{c}\text { 5th percentile } \\
\text { (beats/minute) }\end{array}$ & $\begin{array}{c}\text { 95the percentile } \\
\text { (beats/minute) }\end{array}$ \\
\hline $40-46$ & 39 & 173 & 3 & 168 & 180 \\
$47-53$ & 42 & 179 & 4 & 174 & 182 \\
$54-60$ & 42 & 182 & 4 & 177 & 188 \\
$61-67$ & 43 & 183 & 4 & 176 & 188 \\
$68-74$ & 43 & 181 & 5 & 175 & 196 \\
$75-81$ & 42 & 180 & 7 & 173 & 190 \\
$82-88$ & 41 & 179 & 7 & 171 & 186 \\
$89-95$ & 38 & 175 & 7 & 167 & \\
\hline
\end{tabular}

SD: Standard deviation

The FHR of singleton bovine fetuses increased non-significantly from Days 40-46 to Days 61-67. After reaching a peak value, the FHR decreased slowly until Days 89-95. There was also an increase in the standard deviation at an advancing stage of development. Especially the difference between the mean and the 95th percentile increased, although the difference remained non-significant.

In this experiment five twin pregnancies could be followed between Days 40 and 95 after AI. The total number of recordings was 37. Out of ten twin fetuses, five were regarded as normal, because one cow with twin pregnancy was diagnosed with Johne's disease after calving and three cows lost one of the fetuses before calving. The mean FHR of these fetuses compared to the single reference curve and the 5th and 95th percentiles can be seen in Fig. 1. 


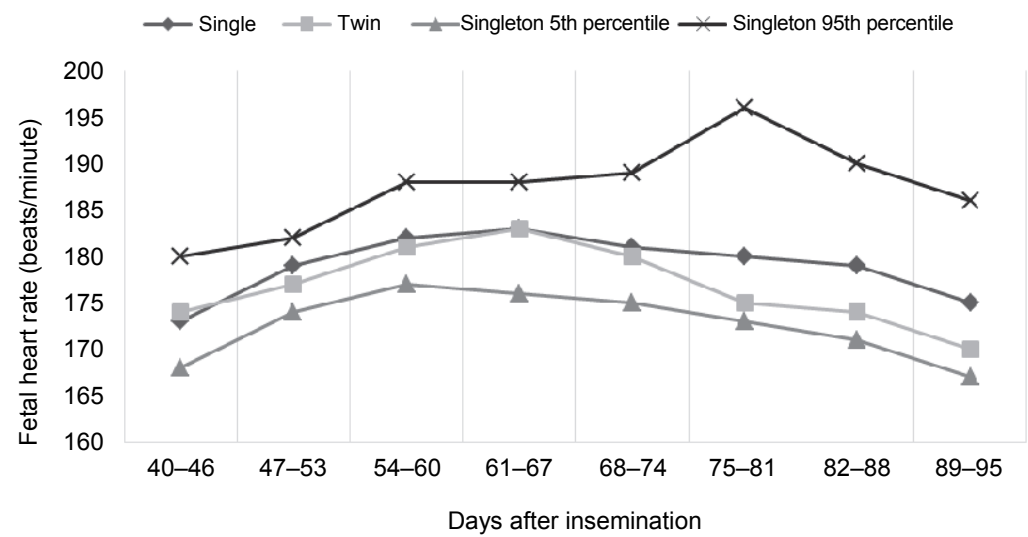

Fig. 1. Comparison of the fetal heart rate of singleton and twin fetuses. The 5th and 95th percentiles of the singleton pregnancy reference curve are also shown

In Fig. 1 it is shown that when comparing singleton and twin fetuses only at the first (days 40-46) and last (days 89-95) examinations, there was no statistically significant effect of twin status and pregnancy date on the number of heartbeats. Although a small difference occurred after Day 74, this also appeared to be statistically not significant.

Three cows with a single pregnancy (cows no. 0766, 1224 and 1658) had an abortion between Days 100 and 220 of gestation. The FHR of these three cows is presented in Fig. 2. One of the aborted fetuses (cow no. 1658) had an increased FHR at several stages of pregnancy compared to the reference curve bordered by the 5 th and 95 th percentiles.

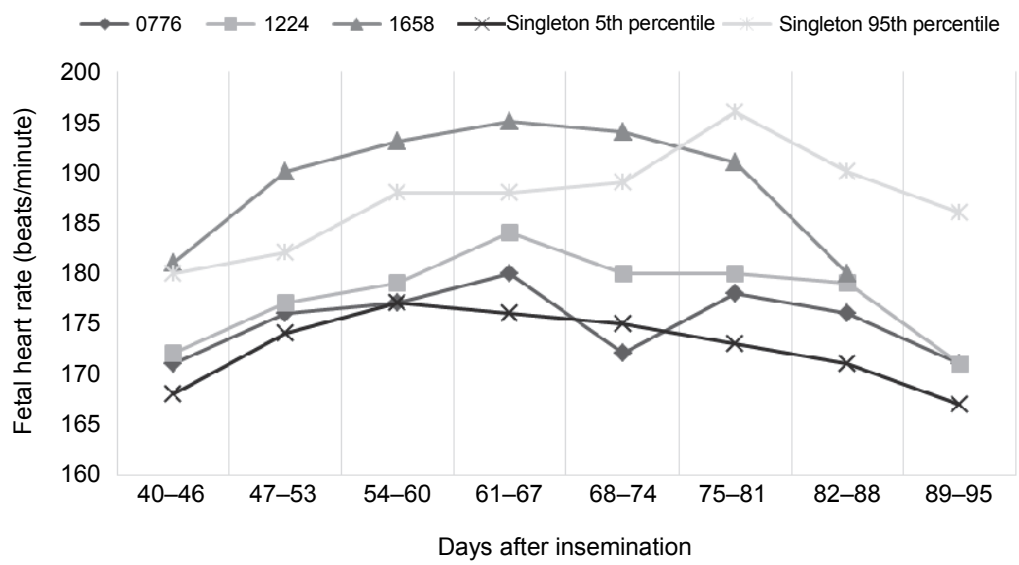

Fig. 2. Comparison of the fetal heart rate in singleton aborted pregnancies (cows no. 0776, 1224 and 1658) with the 5th and 95th percentiles of the singleton pregnancy reference curve 
Three cows with twin pregnancy lost one of the fetuses during gestation. In Fig. 3, the difference between the three lost fetuses and the mean FHR of the five normal twin fetuses can be seen. Only fetus ' 0240 cranial' seems to have a markedly higher FHR around Day 60. This value exceeded the 95th percentile of the single pregnancy reference curve. However, the normal fetus within the same uterus showed a similar peak around Day 60 (data not shown). The FHR of fetus ' 8237 right' decreased markedly after Day 75 . In the third fetus that died in utero (8201 caudal) there was no difference in FHR when compared with the five normal twin fetuses.

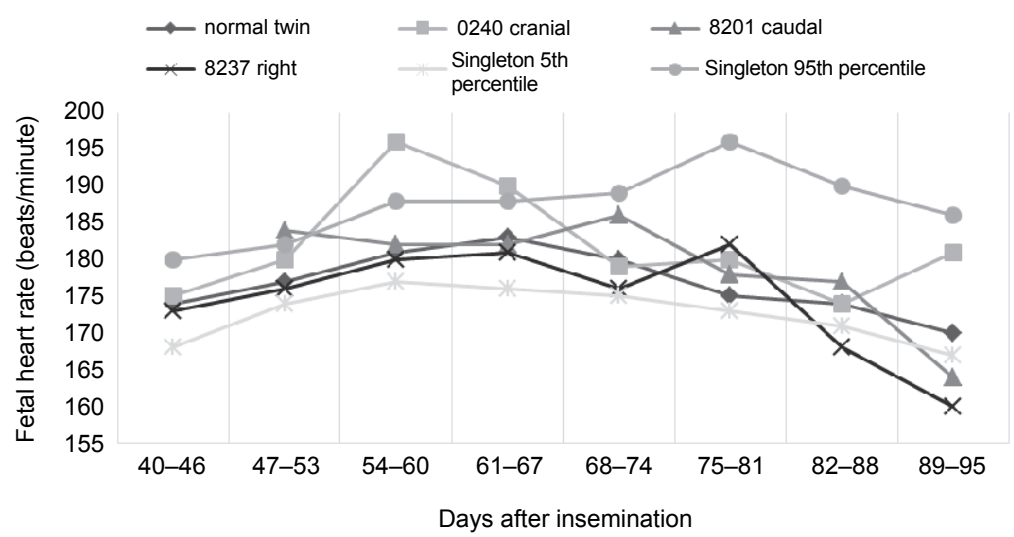

Fig. 3. Comparison of the fetal heart rate (FHR) of lost fetuses from twin pregnancies ( 0240 cranial, 8201 caudal, 8237 right) and the mean FHR of normal twin fetuses. The 5th and 95th percentiles of the singleton pregnancy reference curve are also shown

\section{Discussion}

Transrectal ultrasonography with a 5.0 and/or a $7.5 \mathrm{MHz}$ transducer appeared to be a suitable method for quantifying the FHR between Days 40 and 95 of gestation. The FHR pattern found in the present study corresponds well with the results of several earlier studies in cattle (Kähn, 1989; Ginther, 1998; Breukelman et al., 2004) but differs from the progressively decreasing mean values reported in heifers and in other species (Pawshe et al., 1994; Martinez et al., 1998; Kheradmand et al., 2005; Mor et al., 2012). The mean FHR levels in the present study were somewhat lower than those reported in a previous experiment (Ginther, 1998) but slightly higher than those of other ones (Breukelman et al., 2004; Kheradmand et al., 2005). This might be associated with the larger number of cows used in our experiment, with the different breeds of the fetuses and/or with the considerable variation between individual fetuses. It should also be noted that in several of the above-mentioned studies it was not always clearly described how the FHR was actually counted. 
The slower HR before Day 60 may be due to the immaturity of the sinoatrial node early on, or the atrial pacemaker may actually be slower early in gestation (Shenker et al., 1986). We found an increase in the variability of the FHR during the third month of gestation, as reflected by an increase of the standard variation of the mean value. This may suggest that at an advanced stage of gestation more factors may start to influence the FHR. One of these factors could be fetal mobility. Fetal movements might lead to an increase of the FHR (Ginther, 1998). This is probably also the explanation for the bigger differences between the mean and 95th percentile values, compared to the differences between the 5th percentile and the mean values. Fetal movements could have easily led to temporary peaks in some of the records. This implies that classifying the movement of the fetus before or during FHR recordings could be very useful.

The FHR curves of singleton pregnancies and twin pregnancies are remarkably similar before Day 75. This leads to the conclusion that the number of fetuses in the uterus does not influence the FHR during this period of the first trimester. After Day 74 a difference of some 5 beats/min appeared to develop but more data are needed to clarify if this is a significant pattern. The values of the twin FHRs also differ from the results of a previous study (Bertolini et al., 2002). In our experiment the mean FHR of healthy twins was lower compared to the FHR of in vitro produced twins, but the difference may be the result of a compensatory mechanism of placental insufficiency already described in in vitro produced fetuses (Bertolini et al., 2002).

In our study, three cows $(0776,1224,1658)$ carrying singletons had an abortion while another three (0240 cranial, 8201 caudal, 8237 right) lost one of the twins. In a recent study (Cockcroft and Sorrell, 2015), a total of $20.4 \%$ of cows diagnosed with twins experienced a single reduction during gestation while in other studies the prevalence rates for losing a single fetus were 6.2\% (LópezGatius and Hunter, 2005) and 11.2\% (Silva-del-Río et al., 2009), respectively. Two of the fetuses $(1658,0240$ cranial) showed an FHR that exceeded the 95th percentile, and three (776, 8201 caudal, 8237 right) had an FHR lower than the 5 th percentile at one point. This finding seems to correspond with the results of human studies where changes in the FHR are prognostic predictors of pregnancy loss, but mainly bradycardia is described (Oztekin et al., 2009). In our experiment both bradycardia and tachycardia were detected.

\section{References}

Bertolini, M., Mason, J. B., Beam, S. W., Carneiro, G. F., Sween, M. L., Kominek, D. J., Moyer, A. L., Famula, T. R., Sainz, R. D. and Anderson, G. B. (2002): Morphology and morphometry of in vivo- and in vitro-produced bovine concepti from early pregnancy to term and association with high birth weights. Theriogenology 58, 973-994. 
Breukelman, S. P., Reinders, J. M. C., Jonker, F. H., de Ruigh, L., Kaal, L. M., van Wagtendonkde Leeuw, A. M., Vos, P. L., Dieleman, S. J., Beckers, J. F., Perényi, Z. and Taverne, M. A. (2004): Fetometry and fetal heart rates between Day 35 and 108 in bovine pregnancies resulting from transfer of either MOET, IVP-co-culture or IVP-SOF embryos. Theriogenology 61, 867-882.

Breukelman, S. P., Szenci, O., Beckers, J. F., Kindahl, H., Mulder, E. J., Jonker, F. H., van der Weijden, B., Revy, D., Pogany, K., Sulon, J., Némedi, I. and Taverne, M. A. (2005): Ultrasonographic appearance of the conceptus, fetal heart rate and profiles of pregnancyassociated glycoproteins (PAG) and prostaglandin F2alpha-metabolite (PGF2alphametabolite) after induction of fetal death with aglepristone during early gestation in cattle. Theriogenology 64, 917-933.

Cockcroft, P. D. and Sorrell, E. J. (2015): Twinning in Holstein-Friesian dairy cows: Proportion carried to term and calf sex ratios. Vet. Sci. 2, 131-134.

Curran, S. (2000): Reproductive ultrasound in a dairy practice. Atti della Società Italiana di Buiatria 32, 55-62.

Curran, S., Pierson, R. A. and Ginther, O. J. (1986): Ultrasonographic appearance of the bovine conceptus from days 20 through 60. J. Am. Vet. Med. Assoc. 189, 1295-1302.

Ginther, O. J. (1998): Ultrasonic imaging and animal reproduction: Cattle. Equiservices Publishing, Cross Plains, USA.

Kastelic, J. P., Curran, S., Pierson, R. A. and Ginther, O. J. (1988): Ultrasonic evaluation of the bovine conceptus. Theriogenology 29, 39-54.

Kähn, W. (1989): Sonographic fetometry in the bovine. Theriogenology 31, 1105-1121.

Kheradmand, A., Batavani, R. A. and Farrokhi Ardabili, F. (2005): Comparative sonographic fetometry in dairy cattle. Iranian J. Vet. Res. 6, 47-51.

Martinez, M. F., Bosch, P. and Bosch, R. A. (1998): Determination of early pregnancy and embryonic growth in goats by transrectal ultrasound scanning. Theriogenology 49, 1555-1565.

Mor, S. K., Luthra, R. A., Haldhar, A. and Chandolia, R. K. (2012): Real time ultrasonographic assessment of fetal heart rates in early pregnancy mares. Intas Polivet 13, 145-147.

López-Gatius, F. and Garcia-Ispierto, I. (2010): Ultrasound and endocrine findings that help to assess the risk of late embryo/early foetal loss by non-infectious causes in dairy cattle. Reprod. Dom. Anim. 45, 15-24.

López-Gatius, F. and Hunter, R. H. F. (2005): Spontaneous reduction of advanced twin embryos: Its occurrence and clinical relevance in dairy cattle. Theriogenology 63, 118-125.

Oztekin, D., Oztekin, O., Aydal, F. I., Tinar, S. and Adibelli, Z. H. (2009): Embryonic heart rate as a prognostic factor for chromosomal abnormalities. J. Ultrasound Med. 28, 609-614.

Pawshe, C. H., Appa Rao, K. B. C. and Totey, S. M. (1994): Ultrasonographic imaging to monitor early pregnancy and embryonic development in the buffalo. Theriogenology 41, 697-709.

Rabe-Hesketh, S. and Skrondal, A. (2012): Multilevel and longitudinal modeling using Stata (3rd edition). Stata Press, USA.

Shenker, L., Astle, C. and Reed, K. (1986): Embryonic heart rates before the seventh week of pregnancy. J. Reprod. Med. 31, 333-336.

Silva-del-Río, N., Colloton, J. D. and Fricke, P. M. (2009): Factors affecting pregnancy loss for single and twin pregnancies in a high-producing dairy herd. Theriogenology 71, 1462-1471.

This is an open-access article distributed under the terms of the Creative Commons Attribution 4.0 International License (https://creativecommons.org/licenses/by/4.0/), which permits unrestricted use, distribution, and reproduction in any medium, provided the original author and source are credited, a link to the CC License is provided, and changes - if any - are indicated. (SID_1) 